\title{
Endothermy and Activity in Vertebrates
}

\author{
Albert F. Bennett and John A. Ruben
}




\section{Endothermy and Activity in Vertebrates}

\author{
Albert F. Bennett and John A. Ruben
}

Endothermy, the maintenance of a high and constant body temperature by metabolic means, is a striking adaptation in the animal kingdom. Endothermic animals expend great quantities of energy to regulate and maintain internal thermal conditions and functional processes over a wide range of environmental temperatures. In contrast to ectotherms, they are generally warmer than their environment and are often more active animals. Although endothermy appears during intense muscular activity in several otherwise ectothermic organisms, only among mammals and birds is endothermy main- tained even under resting conditions. The energetic cost of this maintenance in these groups is great, and its evolution has required substantial restructuring of many systems of the vertebrate body. In spite of these costs, mammalian and avian endothermy developed along essentially parallel lines among different groups of reptilian ancestors. The selective factors influencing its evolution must have been substantial and highly significant to have made such a profound alteration in the energetics, physiology, and behavior of two major groups of vertebrates. However, there is no general agreement among vertebrate biologists as to what those selective factors were or what the sequence of events culminating in endothermy was.

The evolution of endothermy in mammals and birds has been the subject of considerable speculation $(I, 2)$, and debate has also been raised concerning metabolic thermoregulation among the dinosaurs (3). These discussions are generally based on the assumption that the endothermic condition is the end product of selection for a high and stable body temperature per se. That is to say, the evolution of endothermy was occasioned by only thermoregulatory considerations. Consequently, attention has been centered upon the advantages of a relatively high and constant body temperature. Among the benefits cited are stability of enzymatic catalysis, independence of timing daily activity, and resistance to freezing $(I)$. These selective factors are not necessarily significant or even advantageous in all environmental circumstances in which endothermy evolved. Thus, arguments for the evolu-

Dr. Bennett is associate professor of biological sciences at the University of California, Irvine 92717. Dr. Ruben is assistant professor of zoology at Oregon State University, Corvallis 97331. 
tion of endothermy based on thermoregulatory considerations alone tend to be ad hoc rather than a uniform explanation equally applicable to all groups. We suggest that thermoregulation was not the vertebrates (fish, amphibians, and reptiles) and the invertebrates (4). Differences in standard metabolic rates among these animals are due principally to variation in body mass and temper-

Summary. Resting and maximal levels of oxygen consumption of endothermic vertebrates exceed those of ectotherms by an average of five- to tenfold. Endotherms have a much broader range of activity that can be sustained by this augmented aerobic metabolism. Ectotherms are more reliant upon, and limited by, anaerobic metabolism during activity. A principal factor in the evolution of endothermy was the increase in aerobic capacities to support sustained activity.

sole selective advantage behind the evolution of the endothermic condition and was, perhaps, not even the initial factor that began its evolution. We believe that this process was directly linked with the development of high activity that was sustained by aerobic metabolism.

\section{Cost of Endothermy}

Hypotheses based only on thermoregulatory considerations fail to justify in selective terms the great increments in energy consumption demanded by endothermy. The rate of resting metabolic expenditure is similar among all groups of ectothermic animals, including the lower

ature. Since this condition is so widespread phylogenetically, it is reasonable to assume that this is the metabolic grade or level from which the ancestors of the endothermic groups departed. Basal metabolic rate in extant mammals and birds is considerably greater. A mammal or bird requires five to ten times more energy for its maintenance than a reptile or other vertebrate ectotherm of similar size and body temperature $\left(38^{\circ}\right.$ to $\left.40^{\circ} \mathrm{C}\right)$ (4-7). This higher rate of heat production, coupled with a low thermal conductance, is the basis of endothermy and it exists even when the differences in body temperature between ectotherms and endotherms are eliminated. Thus, high body temperature alone does not es-

Table 1. Maximum aerobic power elicited by activity in small vertebrates.

$\begin{array}{llll}\text { Species } & \begin{array}{c}\text { Mass } \\ (\mathrm{g})\end{array} & \begin{array}{l}\text { Aerobic } \\ \text { power } \\ (\mathrm{mW} / \mathrm{g})\end{array} & \text { Reference }\end{array}$

\footnotetext{
Sockeye salmon (Oncorhynchus nerka)

Largemouth bass (Micropterus salmoides)

Rainbow trout (Salmo gairdneri)

Goldfish (Carassius auratus)
}

Fish

$\begin{array}{rr}55 & 3 . \\ 150 & 2 \\ 200 & 2 . \\ 66 & 2 .\end{array}$

3.9
2.1
2.3
2.5

40

41

42

43 Amphibians

Spadefoot toad (Scaphiopus hammondi)
Great Plains toad (Bufo cognatus)
Leopard frog (Rana pipiens)
Green iguana (Iguana iguana)
Racehorse goanna (Varanus gouldii)
Desert iguana (Dipsosaurus dorsalis)
Gopher snake (Pituophis catenifer)
Red-eared turtle (Pseudemys scripta) ii)

40

40

38

Reptiles

800

674

35

548

305

Birds

Budgerigar (Melopsittacus undulatus)

Laughing gull (Larus atricilla)

Fish crow (Corvus ossifragus)

Evening grosbeak (Hesperiphona vespertina)

35
322
275
59

\section{9}

\section{5}

2.8

2.8

5.6

11.2

2.9

5.8

44

44

44

16

36

32

45

46
Mammals

Merriam's chipmunk (Eutamias merriami)

Norway rat (Rattus norvegicus)

House mouse (Mus musculus)

Fruit bat (Pteropus gouldii)

$\begin{array}{rr}75 & 39 \\ 286 & 27 \\ 34 & 52 \\ 779 & 60\end{array}$

171
71
83
190

39
27
52
60

31

31

47

15

48

49

49

50
*Aerobic power was calculated at $20.9 \mathrm{~J}$ per milliliter of oxygen consumed. Values reported for poikilotherms were the greatest measured at any body temperature. Values for flying animals are the greatest reporttherms were the greatest measured at any body temperature. Values for flying animals are the greatest report$(m$, mass) $(6,14,15)$. tablish equivalent metabolic rates. This factorial differential is maintained even if body temperature decreases, as during torpor or hibernation, or during experimental depression of body temperature (5). Under most circumstances, however, as ambient temperature decreases, the body temperature of the endotherm remains constant and that of the ectotherm decreases, thus increasing the metabolic differential between the animals. Consequently, at a temperature of $20^{\circ} \mathrm{C}$, an ectothermic vertebrate utilizes only 2 to 3 percent of the energy required by an endotherm and, at $10^{\circ} \mathrm{C}$, only 1 percent (if we assume thermoneutrality in the endotherm and a temperature coefficient of 2.5 for ectothermic metabolism). Thus, depending on environmental temperature, an endotherm expends a great deal of energy for thermoregulation alone, an amount that has been estimated to be as high as 80 to 90 percent of total energy intake of a rodent active under natural conditions (7). In animals active in nature, the size of the metabolic differential between a behaviorally thermoregulating lizard and a mammal or bird of the same size is 20 - to 30 -fold or more (8).

The advantages of endothermy are, therefore, not an unmixed blessing since they entail so great a cost. This is particularly true since energy devoted to physiological thermoregulation could otherwise have been allocated to growth or reproduction (9), which would seem to be of much more direct importance to the reproductive success and fitness of an organism. If an animal attempted to increase its food intake by 5 - to 20 -fold or more, it would at the same time increase its exposure to danger. Even doubling food intake and metabolic rate would be difficult, and significant thermostability is not attained in modern reptiles by such an increment $(2,10)$. It is difficult to conceive of these metabolic increments occurring for strictly thermoregulatory purposes, particularly at the initial stages of the evolution of endothermy when they would have been ineffective in establishing thermostability. Such alterations seem especially unlikely if endothermy evolved in the early Mesozoic, the most thermally equable period in the history of the earth $(I I)$. We suggest that other selective factors were also influential in increasing metabolic levels during the development of endothermy and that these factors relate to the pattern of metabolic support for activity, specifically the augmentation of aerobic capacities. 


\section{Aerobic Capacity}

As physical activity increases, power requirements are met by augmented aerobic metabolism. After an initial lag phase, organismal oxygen consumption rises in proportion to demand. If energetic demands exceed the support capacity of aerobic systems, anaerobic metabolism is used to supplement energy input. In vertebrates, anaerobic metabolism involves principally (if not exclusively) the production of lactic acid.

Among the ectothermic vertebrates, maximal oxygen consumption and aerobic scope (12) are proportionately as low as resting oxygen consumption in comparison to the aerobic capacities of endotherms (13). During maximal activity, oxygen consumption in the lower vertebrates can be increased an average of five- to tenfold at any single body temperature. Thus, at body temperatures characteristic of mammals and birds, levels of oxygen consumption in maximally active ectotherms are equal to resting levels of oxygen consumption in the former groups.

Mammals and birds during activity are also capable of increasing oxygen consumption by an average of five- to tenfold $(14,15)$. The levels of aerobic metabolism achieved by endotherms are thus considerably in excess of those attained by lower vertebrates. For example, resting and maximal rates of oxygen transport in a 1-kg lizard (Iguana iguana) at $35^{\circ} \mathrm{C}$ are 2 and $9 \mathrm{ml}$ of oxygen per minute, respectively ( $/ 6)$; comparable values for a $1-\mathrm{kg}$ mammal are 9 and $54 \mathrm{ml}$ of oxygen per minute (14). The absolute increments (aerobic scopes) are very different ( $4 \mathrm{ml}$ compared to $45 \mathrm{ml}$ of oxygen per minute). Consequently, the capacity of endotherms for supporting work aerobically exceeds that of the lower vertebrates by an order of magnitude (Table 1). Although the resting maintenance requirements of the ectothermic vertebrates are considerably lower, part of the price of that energetic economy is an inability to maintain high levels of aerobic power input.

Thus there appears to be a consistent linkage between resting and maximal levels of oxygen consumption in the vertebrates. When an animal is in any given physiological state, oxygen consumption may increase an average of only five- to tenfold. This generalization is true not only for animals active at normal body temperatures but also for ectotherms over a range of body temperatures; low levels of resting oxygen consumption are associated with low levels of maximal

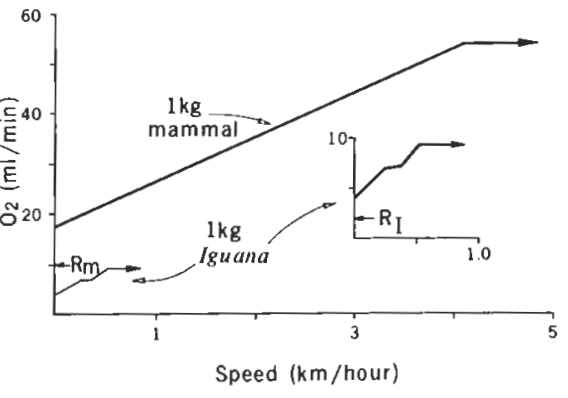

Fig. 1. Oxygen consumption as a function of speed in a green iguana and a mammal (24). $R_{M}$, basal metabolic rate of mammal; $R_{I}$, standard metabolic rate of iguana.

oxygen consumption. Torpid or hibernating mammals are unable to achieve normothermic rates of maximal oxygen consumption until normally active body temperatures have been resumed.

This low factorial increment seems to be a standard feature of vertebrate physiology and may represent a basic limitation of the capacity of the delivery or utilization systems (or both) to process oxygen. For instance, blood circulation rate or the activity of mitochondrial enzymes may be able to increase only fiveto tenfold on a short-term basis. Which system limits maximal oxygen transport in mammals is still very much in debate (I7), and for the other vertebrate classes even less information is available. It is reasonable to assume, however, that these coevolved transport and utilization systems will not differ greatly from each other within an individual animal in their capacity for oxygen processing. Current knowledge does not permit the determination of the mechanisms responsible for this linkage of resting and maximal oxygen consumption in the vertebrates; we can only point out what seems to be a highly consistent pattern. This limitation may be a result of the interposition of several different physiological systems between environmental oxygen and its site of utilization within metabolizing tissues. This factorial limitation in oxygenprocessing ability does not, for example, appear to apply to the insects with a tracheal respiratory system and no involvement of the circulatory system in oxygen transport. Some insects are capable of increasing oxygen consumption 50 to 200 times that at resting levels (18). However, this maximal oxygen consumption cannot be achieved at low body temperature and must be preceded by an increase in tissue temperature to high levels. Torpid mammals and birds are also capable of increasing oxygen consumption by a similar factorial amount. However, several hours are re- quired for complete arousal to maximal activity. Similar arousal takes only minutes in an endothermic insect.

\section{Consequences for Locomotion and}

\section{Sustained Activity}

The differential between maximal aerobic power input in vertebrate endotherms and ectotherms has direct consequences for the level and duration of activity which these animals can sustain. Aerobic metabolic rate in quadruped animals while walking or running increases linearly with speed $(19,20)$. After maximal levels of oxygen consumption are attained, they remain constant at higher speeds. Anaerobic metabolism provides the additional energy required at speeds in excess of that at which oxygen consumption becomes maximal (21). Thus, if two animals have similar costs of locomotion, the animal with the higher aerobic scope will be able to attain and sustain greater speeds aerobically. This situation is evident in comparisons of the locomotor energetics of mammals and lizards. The net cost of transport (22) in terrestrial lizards and mammals is very similar $(19,23)$; however, the mammal is able to sustain much higher speeds. In Fig. 1, oxygen consumption in a l-kg Iguana and mammal are compared (24). Although the lizard expends less energy aerobically while walking at any given speed, the mammal can maintain a broader range of speeds $(0.5 \mathrm{~km} /$ hour for the iguana; $4.1 \mathrm{~km} /$ hour for the mammal).

In comparison to aerobic potential, the cost of locomotion in terrestrial vertebrates is high, and even modest levels of activity quickly outstrip the aerobic scopes of the lower vertebrates. Any activity greater than that of a slow walk in terrestrial ectotherms entails anaerobic metabolism and the production of lactic acid or the net catabolism of high-energy phosphate compounds. The metabolic power that can be obtained anaerobically far overshadows the aerobic abilities of most lower vertebrates, and moderate or high levels of activity in these animals appear to be attainable only with the activation of anaerobiosis (25). These anaerobic processes are capable of supporting muscle contractions for rather short periods, namely, 2 to 5 minutes. Consequently, these animals lack stamina for even moderate activity and exhaust quickly. Recovery takes a long time and hours are sometimes required for complete restoration of the preactive physiological state (13). 
The activity capacities of the lizard Cnemidophorus murinus illustrate the behavioral and locomotor consequences of this pattern of metabolic support (26). This lizard belongs to the saurian family Teiidae, one of the most active groups of extant lizards. Cnemidophorus murinus (approximately $100 \mathrm{~g}$ as an adult) is a highly alert, constantly foraging animal, unlike many other lizards that are sitand-wait predators.

This is consequently a species that might be expected to maximize aerobic potential. However, the oxygen consumption of Cnemidophorus murinus, when walking on a motor-driven treadmill, becomes maximal at only $0.3 \mathrm{~km} /$ hour. At greater speeds, anaerobic metabolism is activated, and this lizard reaches exhaustion in less than 5 minutes when walking at only $0.5 \mathrm{~km} /$ hour. These speeds are very slow, both in absolute terms and in comparison to short-term activity in this species. Speeds of $3.2 \mathrm{~km} /$ hour can be maintained for 1 minute, with bursts up to $8.2 \mathrm{~km} /$ hour over shorter distances. Thus, although aerobic abilities and stamina are limited, a substantial increase in activity can be obtained anaerobically, and speeds can be increased 10 - to 30 -fold over aerobically supportable levels. This activity, however, cannot be sustained. Anaerobic metabolism during activity can supplement, but not supplant, aerobic metabolism.

The anaerobic component provides more scope for activity in ectotherms than in endotherms. Maximal speeds in running mammals are generally only about twice sustainable levels (27), in comparison with 10 - to 30 -fold increments found in lizards $(26,28)$. Thus, the capacities for, and consequences of, anaerobiosis play a greater role in influencing behavior in the lower vertebrates than in mammals and birds. The ectothermic ancestors of the endothermic groups would likewise have been subject to these behavioral constraints of low stamina.

Table 2. Production of adenosine triphosphate (ATP) during 5 minutes of maximal activity in reptiles and rodents (34).

\begin{tabular}{|c|c|c|c|c|c|}
\hline \multirow{2}{*}{ Animal } & \multirow{2}{*}{$\begin{array}{c}\text { Mass } \\
(\mathrm{g})\end{array}$} & \multicolumn{3}{|c|}{ Production of ATP $(\mu \mathrm{mole} / \mathrm{g})$} & \multirow{2}{*}{ Reference } \\
\hline & & Aerobic & Anaerobic & Total & \\
\hline Montane vole (Microtus montanus) & 25 & 40 & 13 & 53 & 51 \\
\hline $\begin{array}{l}\text { Meriam's kangaroo rat } \\
\text { (Dipodomys merriami) }\end{array}$ & 35 & 98 & 9 & 107 & 51 \\
\hline $\begin{array}{l}\text { Western fence lizard } \\
\text { (Sceloporus occidentalis) }\end{array}$ & 13 & 24 & 22 & 46 & 52 \\
\hline $\begin{array}{l}\text { Coachwhip and racer snakes } \\
\text { (Coluber constrictor and } \\
\text { Masticophis flagellum) }\end{array}$ & 262 & 23 & 29 & 52 & 53 \\
\hline
\end{tabular}

before significant thermostability is attained. At some point after the initial metabolic increments, thermoregulatory considerations will become important and, in fact, feasible, whereas previously they were not. The advantages of a high and stable body temperature would then have caused the development of thermoregulatory features, such as fur or feathers. These would retain the metabolically produced heat in cool environments and serve to reduce absorption of heat from warm environments.

The tendency for mammals and birds to regulate body temperature at comparatively high levels may also be related to increasing aerobic capacity during activity. Maximal oxygen consumption and aerobic scope are temperature dependent and generally increase as body temperature increases in ectothermic animals $(6,12,13)$. Both factors are maximal at either preferred thermal levels or at the highest body temperatures tolerated in extant reptiles. Transport or other physical activities require a certain power input regardless of body temperature. Thus, a greater range of speeds and a greater variety of activities may be sustained aerobically at higher temperatures. Greater stamina and aerobically supported performance have been demonstrated in Iguana as body temperature rises (24). Selection operating to increase aerobic capacity would also favor the development of regulation at high body temperatures where oxygen-transport capabilities are maximal and a greater range of aerobic performance is possible.

Another observation concerning the role of thermoregulation in the evolution of endothermy should be mentioned. If thermoregulation, particularly in an equable environment, were the selective feature of greatest importance, it could have been obtained without the alteration of the primitive reptilian physiological condition. The capacities of the ventilatory, respiratory, and enzymatic systems of extant reptiles are fully capable of sustaining resting levels of endothermic metabolism (29). All that would have been required is the development of an insulating coat and the full activation of oxygen-processing systems. Such a reptile would have had a greatly reduced aerobic scope but would have had functional anaerobic systems to support short-term activity. Thus, that the oxygen delivery and utilization systems were greatly increased seems to us to indicate that the evolution of increased aerobic metabolism for the sake of expanded potential for sustained activity played an important role in the development of endothermy. 
The comparisons discussed above have been directed mainly toward terrestrial mammals and reptiles, since both have similar locomotory energetics. However, the selectivity arguments apply equally well to the development of endothermy in birds and, perhaps, in dinosaurs. Part of the attractiveness of this hypothesis is that it does not require the development of ad hoc arguments for thermoregulatory advantages of endothermy in different climates for different groups. The greater levels of sustained power input may have been a factor of significance during the evolution of these groups. Flapping flight requires a certain minimal level of power input that is far beyond the aerobic capacity of modern reptiles. For instance, minimum theoretical and empirical power input required for level flight by a $35-\mathrm{g}$ budgerigar ( $\mathrm{Mel}$ opsittacus) is $3.5 \mathrm{~W}(30,31)$. Maximum aerobic power of a desert iguana (Dipsosaurus) of equal size is $0.4 \mathrm{~W}(32)$. To sustain flight with this power input would require wings that are impossibly large and thin. Anaerobic metabolism cannot safely enhance this power input, since fatigue during flight could be disastrous. Consequently, fundamental enhancement in the aerobic metabolic systems was required for the evolution of flying behavior characteristic of modern birds.

Among the dinosaurs, the necessity of physiological thermoregulation has been questioned since animals of such large mass would, in any case, be of relatively constant body temperature (33). If these animals were endothermic or if some groups of dinosaurs were endothermic, the acquisition of their high metabolic rate might have related to enhancing levels of sustainable activity and not to temperature regulation per se.

\section{Performance During Burst Activity}

The evolution of increased aerobic ability and stamina in endotherms does not seem to have greatly increased maximal power output and the capacity for burst activity. Aerobic and anaerobic contributions to 5 minutes of burst activity are summarized in Table 2 for small rodents and reptiles. Maximal energy utilization over short periods is similar in these animals and is definitely not an order of magnitude different. The anaerobic component becomes even more prominent when shorter time periods are considered since more than half of the anaerobic response occurs during the first 30 seconds of activity (34), and there is an initial lag during this period before maximal levels of oxygen consumption are attained. Consequently total power input of small reptiles may even exceed that of small mammals during shorter periods of activity. These high levels of anaerobically supported power input can result in high levels of short-term behavioral performance. Small lizards can accelerate to speeds greater than $10 \mathrm{~km}$ / hour in distances of less than $2 \mathrm{~m} \mathrm{(28)}$. Although quantitative measurements are generally lacking, maximal speeds of small lizards seem very similar to those of mammals of equal size (35).

Power input and running performance levels during burst activity may thus be very similar in small reptiles and mammals. These relationships explain why reptiles and amphibians are often very fleet and difficult to catch and why they may be able to outperform and outrun endotherms over short distances. The acquisition of high aerobic levels improved capacities for stamina but not for burst activity. Consequently, ectothermic vertebrates were not and are not necessarily easy prey for endotherms. Their lower energy expenditure for maintenance and thermoregulation and greater efficiences of secondary production permit them to occupy niches closed to endotherms. Yet their patterns of activity metabolism permit them to escape from and sometimes pursue endotherms over short distances. The evolution of endothermy has thus not improved all types of activity performance but only those relating to sustained behavior.

\section{Enhancement of Aerobic Capacities}

How might the evolution of increased aerobic capacity have occurred? An examination of the diversity of modern reptiles can suggest adjustments possible within the reptilian metabolic framework. The most active species may be expected to have maximized their potential for oxygen transport. Lizards of the genus Varanus are examples of these capacities. These are active, predatory animals with aerobic scopes and sustainable running speeds more than twice as great as lizards of similar size $(2,36)$. This increment appears to be due to a greatly increased surface area of the lung, highly effective blood buffers, and large amounts of myoglobin in skeletal muscles $(29,36,37)$.

Further increments in oxygen processing ability would appear to require energetic investments in morphological structures associated with oxygen uptake and transport-for example, development of an even more complex lung and ventilation system, the subdivision of the heart and a great increment in blood flow and pressure, and an increase in oxygen-carrying capacity of the blood. In addition, the capacity of tissue to utilize oxygen was also increased. Skeletal muscle, the tissue with the greatest aerobic scope, is the principal consumer of oxygen during activity. However, skeletal muscle has a relatively low metabolic rate at rest and does not constitute a major thermogenic organ in resting mammals (38). Endothermy is not based on muscle metabolism alone but involves increments in the metabolic rates of many organs. The activity of mitochondrial enzymes in unpurified homogenates of liver and skeletal muscle from lizards and mammals parallels differences in aerobic metabolic rates of intact animals (39). The greater metabolic rate of the endotherm appears to be due to greater concentrations of mitochondria in its tissues. If the catalytic capacity of the mitochondrial enzymes represented a major limitation on the oxygen-processing ability of animals evolving higher metabolic rates, this capacity could have been increased with a minimum of genetic alteration by increasing mitochondrial volume.

All the preceding alterations are consonant with increasing capacity for both activity and physiological thermoregulation. We believe that these events were tightly related and that the latter would not have occurred without the former.

\section{References and Notes}

1. R. B. Cowles, Evolution 12, 347 (1958); J. E. Heath, in Evolution and Environment $\mathrm{E}$ T. Drake, Ed. (Yale Univ. Press, New Haven, Conn., 1968), p. 259; J. A. Hopson, Am. Nat. 107,446 (1973); B. K. McNab, ibid. 112, I (1978); A. W. Crompton, C. R. Taylor, J. A. Jagger, Nature (London) 272, 333 (1978).

2. G. A. Bartholomew and V. A. Tucker, Physiol. Zool. 36, 199 (1963); ibid. 37, 341 (1964).

3. R. T. Bakker, Evolution 25, 636 (1971); Nalure (London) 238, 81 (1972); A. J. Desmond, The Hot Blooded Dinosaurs (Blond \& Briggs, London, 1975); A. J. de Ricqlès, in Morphology and Biology of Reptiles, A. d'A. Bellairs and C. B. Cox, Eds. (Academic Press, New York, 1976), p. 123 .

4. A. M. Hemmingsen, Rep. Steno Mem. Hosp. Nord. Insulinlab. 9, 1 (1960).

5. F. G. Benedict, Carnegie Inst. Washington Bartholomew, Physiol. Zool. 29, 40 (1956).

6. The following regression equations relate resting metabolic rate to mass $(M$, metabolic rate in watts; $x$, mass of animal in kilograms); for lizards at $37^{\circ} \mathrm{C}, M=0.69 x^{0.82}$; mammals, $M=3.40 x^{0.75} ;$ nonpasseriform birds, $M=3.79$ $x^{0.72}$ [from, respectively, A. F. Bennett and $W$. R. Dawson, in Biology of the Reptilia, C. Gans R. Dawson, in Biology of the Reptilia, C. Gans
and W. R. Dawson, Eds. (Academic Press, New York, 1976), vol. 5 (Physiology A), p. 127; M. Kleiber, The Fire of Life (Wiley, New York, 1961); R. C. Lasiewski and W. R. Dawson, Condor 69, 13 (1967)].

7. B. K. McNab, Ecology 44, 521 (1963).

8. A. F. Bennett and K. A. Nagy, ibid. 58, 697 (1977).

9. The efficiency of secondary productivity (calories of tissue formed per calories assimilated) is an order of magnitude greater in poikilotherms than in homeotherms [F. B. Golley, Am. Zool. 8,53 (1968); S. McNeill and J. H. Lawton, $N a-$ ture (London) 225, 472 (1970)].

10. Assuming minimal values of thermal conductance and doubling resting levels of metabo- 
lism [from (2)], a gradient of only $1^{\circ} \mathrm{C}$ is maintained between the core body temperature and ambient temperature in the lizards Amphibo lurus and Varanus.

11. M. Schwarzbach, in Descriptive Paleoclima tology, A. E. Nairn, Ed. (Intersciences, New York, 1961), p. 266; L. C. King, in ibid., p. 325; Y. Boucot, personal communication.

12. Aerobic metabolic scope is the difference between maximal and minimal oxygen consump tion [F. E. J. Fry, Publ. Ontario Fish. Res. Lab. 68, $1(1947)]$.

13. See A. F. Bennett [Annu. Rev. Physiol. 40, 447 (1978)] for a review of activity metabolism in the lower vertebrates.

14. A. J. Lechner, Respir. Physial. 34, 29 (1978).

15. M. Berger, J. S. Hart, O. Z. Roy, Z. Vgl. Physiol. 66, 201 (1970)

16. W. R. Moberly, Comp. Biochem. Physiol. 27, 1 (1968).

17. J. O. Holloszy, Exercise Sport Sci. Rev. 1, 45 (1973); Limiting Factors of Physical Performance, J. KeuI, Ed. (Thieme, Stuttgart, 1973).

18. A. KTogh, Comparative Physiology of Respiratory Mechanisms (Univ. of Pennsylvania Press, Philadelphia, 1941), p. 129; T. M. Casey, J. Exp. Biol. 64, 529 (1976); G. A. Bartholomew and T. M. Casey, Science 195, 882 (1977).

19. K. Schmidt-Nielsen, Science 177, 222 (1972); C $\mathrm{R}$. Taylor, in Comparative Physiology: Locomo tion, Respiration, Transport and Blood, $\mathrm{L}$ Bolis, K. Schmidt-Nielsen, S. H. P. Maddrell, Eds. (Else vier, New York, 1973), p. 23.

20. C. R. Taylor, K. Schmidt-Nielsen, J. C. Raab Am. J. Physiol. 219, 1104 (1970).

21. The velocity at which anaerobic metabolism is activated is termed the "anaerobic threshold." It may occur below the velocity at which oxygen consumption is maximized.

22. The slope of oxygen consumption as a function of velocity; see (19).

23. R. T. Bakker, Physiologist 15, 76 (1972).

24. Basal and maximal values of mammalian oxygen consumption are taken from $(l 4)$, intercept and cost of transport, from (20). Values for Iguana are from W. R. Moberly [Comp. Biochem. Physiol. 27, 21 (1968)] and from (l6).

25. A. F. Bennett and P. Licht, Comp. Biochem. Physiol. A 48, 319 (1974).

26. A. F. Bennett and T. T. Gleeson, Copeia 1979 573 (1979).

27. A. V. Hill, Sci. Prog. (London) 38, 209 (1950).

28. A. F. Bennett, Anim. Behav., in press.

29. $\longrightarrow$ Comp. Biochem. Physiol. A 46, 653 (1973).

30. C. J. Pennycuick, Ibis 111, 525 (1969).

31. V. A. Tucker, J. Exp. Biol. 58, 689 (1973)

32. A. F. Bennett and W. R. Dawson, J. Comp. Physiol. 81, 289 (1972)

33. J. R. Spotila, P. A. Lommen, G. S. Bakken, D. M. Gates, Am. Nat. 107, 391 (1973)

34. Values are calculated on whole body measurements of oxygen consumption and lactic acid formation during 5 minutes of electrically or mechanically stimulated activity in closed containers. Formation of adenosine triphosphate (ATP) is calculated at $290 \mu$ mole of ATP per milliliter of $\mathrm{O}_{2}$ consumed and $16.7 \mu$ mole of ATP per milligram of lactic acid formed [see A. F. Bennett and P. Licht, J. Comp. Physiol. 81, 277 (1972)].

35. J. Gray, Animal Locomotion (Norton, New York, 1968), p. 156.

36. A. F. Bennett, J. Comp. Physiol. 79, 259 (1972)
37. $\longrightarrow$, Comp. Biochem. Physiol. A 46, 673

38. J. Aschoff, B. Günther, K. Kramer, Energie hausholt und Temperaturegulation (Urban \& Schwarzenberg, Munich).

39. A. F. Bennett, Comp. Biochem. Physiol. B 42 $637(1972)$.

40. J. R. Brett, J. Fish. Res. Board Can. 21, 1183

41. F. W. H. Beamish, Can. J. Zool. 48, 1221 (1970)

42. I. W. Dickson and R. H. Kramer, J. Fish. Res. Board Can. 28, 587 (1971).

43. H. Smit. J. M. Amelink-Koutstaal, J. Vijverberg, J. C. von Vaupel-Klein, Comp. Biochem. Physiol. 39, 1 (1971).

44. R. S. Seymour, Copeia 1973, 103 (1973).

45. O. E. Greenwald, ibid. 1971 , p. 98 (1971).

46. R. E. Gatten, Jr., Comp. Biochem. Physiol. A 48, 619 (1974)

47. M. H. Bernstein, S. P. Thomas, K. Schmidt Nielsen, J. Exp. Biol. 58, 401 (1973).

48. B. A. Wunder, Comp. Biochem. Physiol. 33, 82 (1970).

49. P. Pasquis, A. Lacaisse, P. Dejours, Respir. Physiol. 9, 298 (1970)

50. S. P. Thomas, J. Exp. Biol. 63, 273 (1975)

51. J. A. Ruben and D. E. Battalia, J. Exp. Zool. 207, 73 (1979)

52. A. F. Bennett and T. T. Gleeson, Physiol. Zoo 49. 65 (1976).

53. J. A. Ruben, J. Comp. Physiol. 109, 147 (1976).

54. Supported by NSF grants PCM 75-10100A01 and $77-24208$ and NIH grant 1 KO4 AMO0351-01 (to A.F.B.) and NSF grant DEB 78-10837 (to J.A.R.). We thank G. A. Bartholomew for comments on the manuscript. 